\title{
The Road to Teacher Burnout and its Possible Protecting Factors - A Narrative Review
}

\author{
Eszter Nagya*, Dr. Ildikó Takács ${ }^{\mathrm{b}}$ \\ a Budapest University of Technology and Economics. \\ b Budapest University of Technology and Economics. E-mail: takacsi@erg.bme.hu \\ ${ }^{*}$ Corresponding author's email address: nagyeszter@erg.bme.hu
}

\section{A R T I C L E I N F O}

Received: 11-08-2017

Accepted: 01-10-2017

Available online: 10-10-2017

\section{Keywords:}

Personality characteristics;

Regression analysis;

Teacher burnout;

Work environment.

JEL Classification:

D19; J63.

\begin{abstract}
A B S T R A C T
In this review study personality characteristics and workplace environment variables (with special attention to classroom conditions) are investigated regarding the phenomenon of teacher burnout in order to discover the basis of an effective intervention program. Regarding the studies, the Maslach Burnout Inventory Educational Survey for burnout measurement (Maslach, Schaufeli, \& Leiter, 2001) was applied in all of the researches. Samples have been collected from the USA and several countries of Europe. All of the studies applied the method of either linear or multiple regression analysis. According to the results, workload and social support turned out to be major influencing factors as much as work characteristics are concerned, and positive affectivity, emotional stability and self-efficacy were the major influencing variables as much as personality characteristics are concerned. As a conclusion of the correlating tendencies, a suggested model has been created, in order to understand the process of how an individual responds - according to his or her personality characteristics - to his or her environment - defined by measured work characteristics - in the process of burnout. This model gives a revolutionary viewpoint about the development of burnout syndrome by the combination of work environment factors and personality characteristics, thus contribute to the understanding of the syndrome at a deeper level.
\end{abstract}

This is an open access article under the terms of the Creative Commons Attribution License 4.0, which allows use, distribution and reproduction in any medium, provided the original work is properly cited.

DOI: http://dx.doi.org/10.18533/rss.v2i8.107

ISSN 2378-8569(Print), ISSN 2378-8550(Online)

\section{Introduction}

Teaching is considered to be a helping profession. Teachers experience a lot of emotional stress in their job, there are demands coming from students, the principal, parents and from the government - in the form of regulations - as well (Sas, Boroş, \& Bonchiş, 2011). The challenge that a teacher has to face when entering the profession changes from country to country according to the different cultural backgrounds. One universal feature of the profession is that teachers are responsible for the next generation's personality and cognitive development as well. How teachers perform in their jobs affects how children will see the world after completing their studies. Teachers should be a role model and convey values of a decent and content life. Nowadays teachers are not paid enough attention and in numerous cases as a result a phenomenon called burnout starts to develop. Burnout was first observed in the nursing profession, but teachers are equally at risk as they are in connection with people and support other humans on a daily basis. Burnout refers to a process where work demands and job resources are mismatching. According to Maslach's definition (1982, p.337. in Mazur \& Lynch, 1989), "burnout is a response to the chronic emotional strain of dealing extensively with other human beings, particularly when they were troubled or troublesome". Literature suggests that it is not only the individuals' competences that are relevant in 
the development of burnout, but a socially supportive environment is able to improve one's emotional health as well (Fiorilli et al., 2014; Mazur \& Lynch, 1989).

According to Etzion, another researcher of burnout, burnout is (1987, pp. 16-17., in Schaufeli, W.B.; Buunk, 1996):

"continuous, barely recognizable, and for the most part denied, misfits between personal and environmental characteristics are the source of a slow and hidden process of psychological erosion. Unlike other stressful phenomena, the mini-stressors of misfit do not cause alarm and are rarely subject to any coping efforts. Thus the process of erosion can go on for a long time without being detected."

The first symptoms of burnout are barely noticed by the person him- or herself, especially when one is not conscious about the process of emotional stress. Most of the people at work are familiar with the concept of stress and feeling drained, but with burnout one has to be careful as it develops invisibly, like a psychological erosion. When burnout actually arrives at one's doorstep, one should have effective methods in order to see it as a manageable challenge instead of a burden that can overwhelm the self by time.

Until this point, several studies investigated the phenomenon of teacher burnout in relation with work environment factors and personality factors (e.g.: Bruce, 1996; Byrne, 1991; Goddard, O’Brien, \& Goddard, 2006; Goetz et al., 2015; Skodova \& Lajciakova, 2013), however, there is no study in the scientific literature that has investigated the effects of several work environment factors together with personality characteristics on burnout syndrome. It is important to reveal how personality factors interact with the elements of work environment, which may or may not lead to burnout. For this reason, the aim of this study in one hand is to reveal the characteristics and factors (both work environment and personal traits) that should be recognized during the process of burnout. On the other hand, based on the results and conclusions of the several reviewed studies, we make implications regarding to the interactions of the above-mentioned two phenomena in order to have more understanding about the development of burnout syndrome.

In the present study, first we give an overview about the concept and development of burnout, then main personality characteristics and work environment factors will be introduced in relation with burnout syndrome. After introducing the literature background, results of the reviewed studies will be revealed in a summarized form. At last, the presented results will be discussed and a suggested model will be introduced which explains the interactions of personality characteristics and work environment factors in the development of burnout syndrome.

\section{Literature review}

\subsection{The concept of burnout}

In our investigation, we based our findings on the model of Maslach (Maslach et al., 2001). Maslach and her colleagues defined three main dimensions regarding the process of burnout: emotional exhaustion (when one is in a state of drained energy, feeling unable to respond to emotional requirements at work, feeling angry, frustrated and dissatisfied), depersonalization (dehumanizing the relationships especially with people who expect "personal investment") and personal accomplishment (which is related to either positive or negative selfevaluation and the perceived level of self-efficacy) (Sas et al., 2011). In the case of the teaching profession, educators can experience emotional exhaustion when they perceive that they are not able to be there for their students as much as they could before. By depersonalization, they develop a negative, cynical attitude towards students, colleagues and parents as well. The decrease of personal accomplishment occurs at teachers by means of their perception of their ineffectiveness in being helpful to students and failing to manage other tasks at work (Byrne, 1991).

However, the concept that Maslach developed presented an opportunity for a professional discussion about the construct of burnout. Demerouti (Demerouti, E.; Bakker, A.B.; Nachreiner, F.; Schaufeli, 2001) did not include the personal accomplishment dimension in her model. In the job demands-job resources model, she introduced emotional exhaustion as a result of overwhelming demands of the job, and depersonalization in connection with job resources, as a maladaptive coping strategy. Personal accomplishment was proven to be the weakest dimension of burnout since it had a weaker connection with emotional exhaustion and depersonalization than they had with each other (Demerouti, E.; Bakker, A.B.; Nachreiner, F.; Schaufeli, 2001; Lee \& Ashforth, 1993), and seemed to be an antecedent or an outcome of burnout rather than a determining factor (Reis, Xanthopoulou, \& Tsaousis, 2015). For this reason, other assessment tools were developed for measuring burnout syndrome in order to provide a better psychometric quality than the MBI. The Oldenburg Burnout Inventory (further referred as OLBI) became an alternative solution, as it showed a convergent validity with the General Survey of MBI (MBIGS) (Demerouti, E.; Bakker, A.B.; Nachreiner, F.; Schaufeli, 2001; Reis et al., 2015). It measures emotional exhaustion and depersonalization in two continua, where depersonalization refers to a stage between disengagement and dedication ("identification" continuum), and level of emotional exhaustion indicates either exhaustion or vigor on the continuum of "energy" (Reis et al., 2015). The inventory investigates emotional exhaustion from the cognitive and physical aspect besides the emotional aspect that was solely investigated by MBI. During the development of OLBI, researchers balanced the ratio of positive and negative statements in the 
items (Maslach et al., 2001). Another advantage of OLBI is that it is a measurement tool to be used not only in the human service sector, but can be applied for other occupations as well (Reis et al., 2015). Besides OLBI, other alternative measurements were developed, such as the Copenhagen Burnout Inventory (CBI), and the ShiromMelamed Burnout Measure (SMBM) (Reis et al., 2015), however, OLBI seems to have the highest validity among them.

In this review, teacher burnout is to be explored as a three-dimensional construct, including the dimension of personal accomplishment. Reaching back to the first model of burnout is due to the fact that there is considerable amount of studies that found significant connections between personal accomplishment and its influencing factors regarding burnout (e.g.: J.Burke \& Greenglass, 1995; Lee \& Ashforth, 1993; Leiter, 1993). The validity of MBI is proven by several studies (Alarcon, Eschleman, \& Bowling, 2009; Leiter, 1993), for this reason it can be considered as a "gold standard" for measuring the construct.

\subsection{Development of burnout syndrome}

In order to discover which dimension of burnout is connected to certain personality characteristics and work environment factors, it is necessary to examine the process of burnout development. There are different approaches developed regarding the subject (Fekete, 1991; Hayes, 2013; Maslach et al., 2001). Some of the theories focus both on the interpersonal and the intrapersonal changes of the individual (e.g.: Fekete, 1991), others take only the individual aspect into account (e.g.: Freudenberger, 1974). In order to examine the widest spectrum in burnout, this study investigates the theories that include interpersonal characteristics as well. According to the findings, there are either three or four phases of burnout, beginning with an increased stress related to work. Stress is experienced because the job resources and the job demands do not match (Maslach et al., 2001). In the second phase the stress that is experienced by the individuals affects the interpersonal level. Personal connections start to malfunction. This is a paradox situation, where the person needs the attention and support from the relatives and coworkers, yet his or her behavior starts to change in a way that he or she starts to avoid personal contact (Fekete, 1991). In the third phase there is apathy, emptiness, which is the result both of the person's lacking inner resources to handle the emotional strains at work, and the relationships that are lagging behind (Bergner, 2012). In this phase, the person loses his or her sense of effectiveness at work Maslach et al., 2001). Some of the theories propose job turnover as a last phase, after the third one (Fekete, 1991).

Regarding the burnout dimensions, different phases can be characterized by different levels of the burnout factors. This study investigates the sequence model developed by Maslach and Leiter (Leiter, 1993). Based on their theory, the development model of burnout begins with a high level of emotional exhaustion, which is connected with work stress, a rise in the number of interpersonal conflicts, and the absence of effective skills and coping strategies. As a defensive coping strategy, depersonalization rises in the second phase, influenced by the lack of support (on the side of coworkers and the supervisor), and a decrease in client cooperation can be observed. Reduced personal accomplishment occurs in the last phase. This is connected to the lack of autonomy, social support, client cooperation, coping strategy and skills (Leiter, 1993). According to the phase model of Maslach and Leiter, a conclusion can be made that reduced personal accomplishment is a result of failure in applying adaptive coping mechanisms (Leiter, 1993).

\subsection{Factors related to burnout}

Observations have been made in previous studies by frequent measurement of certain work environment factors related to burnout, such as work overload, role stress, and autonomy at work. Among the personality characteristics, the most frequently investigated constructs are emotional stability, autonomous motivation, conscientiousness and coping strategies of the individuals. The influential effects of these variables can be translated into the special case of teachers' burnout, which narrows the focus of the following exploration. Suggestions will be made on how teachers' occupation can relate to the constructs listed below.

\subsubsection{Personality characteristics}

\subsubsection{The five factor model}

The Five Factor Model by Costa and McCrae (McCrae \& John, 1992) classifies personality characteristics in five dimensions: extraversion, agreeableness, conscientiousness, openness, and emotional stability. In order to have an overview of the factors, a table with each factor and its adjectives can be seen below (Table 1). We introduce four of the factors in this article, since during our literature overview, no studies found connections with the burnout dimensions and the Openness factor in the Five Factor Model. Agreeableness is a construct that can be examined through the interpersonal relations (Leary, 1957 in McCrae \& John, 1992) Regarding agreeableness, researchers found (Mollart, Skinner, Newing, \& Foureur, 2013), that besides its benefits, nurses with high agreeableness tend to say yes to a task at work when they are already over worked. At the same time, Canadas-De la Fuente and colleagues found (Cañadas-De la Fuente et al., 2015), that when emotional exhaustion increases in burnout, agreeableness decreases. Conscientiousness means that the individuals respect norms and regulations, are disciplined, plan their actions and are trustworthy (Colomeischi, 2015). This factor is an indicator for the person-job fit. According to Behling (1998 in Hurtz \& Donovan, 2000), conscientiousness is a main criterion for 
personnel selection. Regarding teachers, conscientiousness is an important personality requirement, as they have to be ethical role models for children. People with high conscientiousness provide safety in the frame of rules and obligations, without favoritism or subjective judgements. Individuals with a high level of extraversion effectively function and have greater sense of well-being not only in an intrapersonal, but also in a social sense. Extraversion predicts resilience against the development of psychopathologic tendencies (Wilt \& Revelle, 2009). Extraverts enjoy being a leader (Blickle et al., 2015), since they are persuasive, outgoing and achievement-motivated. Extraversion as a personality trait can be useful for teachers as they have to be connected with several students at a time, and it is important to enjoy this kind of vivid connection. Emotional stability is the last dimension of the Five Factor Model that we introduce in this article. According to its definition, one with high emotional stability tends to be a positive thinker and an optimist, somebody who controls emotions and is self-confident (Colomeischi, 2015). Teachers' emotional stability results in their confidence and conflict management skills. Teachers' confidence regarding the subject they teach as well as their ability to handle problematic pedagogical situations within the class, roots in their emotional stability.

Table 1: Big Five adjectives from John (1990 in Wilt \& Revelle, 2009)

\begin{tabular}{lllll}
\hline Trait & & & & \\
\hline Extraversion & Agreeableness & Conscientiousness & Neuroticism & Openness \\
\hline talkative & sympathetic & organized & tense & wide interests \\
assertive & kind & thorough & anxious & imaginative \\
active & appreciative & planful & nervous & intelligent \\
energetic & affectionate & efficient & moody & original \\
-quiet & -cold & -careless & -stable & -commonplace \\
-reserved & -unfriendly & -disorderly & -calm & -simple \\
-shy & -quarrelsome & -frivolous & -contented & -shallow \\
-silent & -hard-headed & -irresponsible & -unemotional & -unintelligent \\
\hline
\end{tabular}

\subsubsection{Coping strategy}

Coping refers to a strategy that individuals apply to handle challenging situations (Laugaa, Rascle, \& Bruchon-Schweitzer, 2008). According to a categorization developed by Lazarus and Folkman (1984), there is problem-focused coping, where individuals focus on the problem itself, and make efforts in order to find solutions for that. The other way of coping is emotion-focused coping, when individuals focus on their emotional state as the result of stress, and change their attitude toward the situation. In the case of problem-focused coping, it is easier to overcome the difficulties of the task, while those who deal with emotions may feel that a stressor is something that exceeds their ability to cope (Lazarus \& Folkman, 1984 in Foley \& Murphy, 2015). Regarding the phenomenon of burnout, depersonalization is a form of avoidance coping (Stoeber \& Rennert, 2008 in Fiorilli et al., 2014).

\subsubsection{Core self-evaluation}

Core self-evaluation (referred in the following as CSE) is a construct which describes the individuals' belief about their self-worth and competence to accomplish tasks at work (Alarcon et al., 2009). This personality factor can influence how individuals perceive the work environment in accordance with their self-belief. High CSE individuals tend to perceive a task as a challenge and an opportunity they can succeed in. Individuals with low scores on CSE may perceive that their job tasks are threatening and too difficult to accomplish (Alarcon et al., 2009). The construct of core self-evaluation is built up by four constructs: self-esteem, general self-efficacy, emotional stability and internal locus of control (Judge, Bono, Erez, \& Locke, 2005).

\subsubsection{Positive and negative affectivity (PA and NA)}

Positive affectivity is a tendency to experience positive emotional states, like excitement, happiness and high energy. It is related to the level of engagement in one's connections (Alarcon et al., 2009). It is a protecting factor against dehumanization (depersonalization). Individuals with high level of positive affectivity are likely to seek more challenging jobs and perform better at job interviews since they are more successful in their communication and open to new information about the world (Alarcon et al., 2009). In the case of teachers, when they express genuine positive feelings and enthusiasm, and commitment for the students and for the subject they teach, it creates respect within students toward the teacher. The teacher becomes an inspirational figure and can raise the interest of the students toward the subject, and encourages them to explore with a genuine curiosity toward the world. Negative affectivity is a tendency to experience negative emotions like anxiety, sadness, or hostility. According to several studies (e.g.: Alarcon et al., 2009; Rouxel et al., 2016), it concerns all dimensions of burnout. The strongest connection was found between emotional exhaustion and negative affectivity, which means, that by experiencing negative emotional states, it exhausts the individuals' resources, so they have less energy to cope at different aspects of their lives. 


\subsubsection{Emotional intelligence (EI)}

Emotional intelligence is a much discussed concept, according to Kafetsios and Zampetakis (2008 in Ju et al., 2015), ability EI and trait EI can be distinguished. The study investigated trait EI (i.e.: emotional self-efficacy), which is measured by means of four dimensions: self-emotion appraisals, others' emotion appraisals, regulation of emotion and use of emotion (Ju et al., 2015). Emotional Intelligence was a mediator in the relation of burnout and perceived social support. The researchers discovered that individuals with high emotional intelligence perceive their environment as more supportive, thus they are less susceptible to burnout (as social support is a protecting factor against burnout - as seen in the following). For teachers, a high emotional intelligence is a requirement in order to understand and be able to respond to students' needs.

\subsubsection{The self-determination theory (SDT model)}

Motivational theories related to burnout were investigated by numerous other studies. The SelfDetermination Theory (referred in the following as SDT) by Deci and Ryan (1985 in Fernet et al., 2012) proposes the concept of autonomous motivation which is based on the idea that individuals initiate behavior by their own choice. The theory is based on the concepts of intrinsic and extrinsic motivation. Extrinsic motivation is when behavior is determined by either getting a reward or avoiding a constraint. When individuals' behavior depends on others' expectation, it usually results in an internal conflict, since the individual is not engaged in the activity, and internal values conflict with the expected behavior. Intrinsic motivation is when individuals become autonomously motivated and the behavior means a value for them. According to SDT, it is possible to make extrinsic motivation internalized by realizing the values of the task or activity. Regarding the dimensions of burnout, researchers found (Fernet et al., 2012), that autonomous - intrinsically regulated - motivation can work as a protecting factor as it influences emotional exhaustion in a negative way.

\subsubsection{Work environment factors}

\subsubsection{Social support}

Social support is determined by the work climate (Lee \& Ashforth, 1993). When social support is optimal, the climate which surrounds individuals is trustful, people are open to each other, there is competent supervision and individuals get recognized by peers and supervisors - not only in their profession but also as a person (Lee \& Ashforth, 1993). In the case of teachers, the aspect of "recognition" is worth special attention, because the performance of educators is usually not seen by the principal, who is the supervisor in this case. Since teachers close the door as the class begins, no one else can confirm whether they are doing a great job or perform poorly. Despite this fact, social support was recognized to be a major influencing factor of burnout (Alarcon et al., 2009; J.Burke \& Greenglass, 1995; Lee \& Ashforth, 1993; Mazur \& Lynch, 1989), correlating with all dimensions of burnout. However, social support can be interpreted in different ways. It can come from peers (colleagues), family, friends or the supervisor at work. In job burnout, studies measured the influence of support regarding the workplace (coming from colleagues and the supervisor). In most cases studies found that both colleagues' and supervisors' support has a decreasing effect on burnout (Lee \& Ashforth, 1993). However, Mittal (Mittal \& Chhabra, 2011) found that support coming from colleagues is in positive relation with emotional exhaustion, and support coming from the supervisor is related negatively to emotional exhaustion. This finding may cast a shadow on the concept of support, as it implies that not every kind of connection is worth being kept active (especially those that drain one's energy). Too much connection with colleagues may divert the attention away from the important tasks at work, thus individuals may feel a decrease of self-efficacy. According to the studies, a competent and relevant supervisor can have the effect of reducing burnout syndrome, as it has an influence on all of its dimensions (emotional exhaustion and depersonalization is in negative relation and personal accomplishment is in positive relation with it) (Fiorilli et al., 2014; Mazur \& Lynch, 1989). Another important finding is that availability of the support rather than actual support coming from the supervisor has an influence on the level of burnout (Lee \& Ashforth, 1993). The support system may function as a "safety net", and only by making sure that support is available if needed, makes individuals less threatened by stressful situations.

\subsubsection{Relations between social support and role stress}

The phenomenon of social support was investigated together with role stress. Role stress is proven to be a major influencing factor for the early phase of burnout (Gil-Monte, Peiro, \& Valcárcel, 1998; J.Burke \& Greenglass, 1995; Lee \& Ashforth, 1993; Mazur \& Lynch, 1989). Role stress has two components: role ambiguity and role conflict. Role ambiguity means that there are no clear instructions and expectations coming from the supervisor, and employees are unsure about their everyday tasks (Sun, Gao, Yang, Zang, \& Wang, 2016). It can raise the level of frustration. Role conflict is when the individuals experience opposing expectations either from outer aspects of their life (e.g.: family and work), or there is an inner conflict between their values and the expected behavior (Maslach et al., 2001).

It is not clear from the findings how support connects with role stress (i.e.: role conflict and role ambiguity). On the one hand, Lee and Ashforth (1993) found that social support affects burnout through role stress. It reflects on the finding (mentioned above) that inadequate feedbacks in social connections can weaken 
rather than strengthen the individuals' ability to cope with work stress. This hypothesis is supported by another finding, the study of Shinn et al. (1984 in Lee \& Ashforth, 1993). In this study, it was proven that social support is the mediator between role stress and burnout rather than role stress is a mediator between the other two phenomena. This result implies that problem-focused support has a protecting value against emotional exhaustion, and emotion-focused support is possible to enhance the emotional strain of work.

\subsubsection{Autonomy at work}

Another variable that has been investigated in connection with burnout is autonomy. It refers to the level of freed om that the individuals achieve and prioritize their tasks at work determined by themselves (Leiter, 1993). In the case of teachers, autonomy can be interpreted in the classroom environment and their instructional activity. On the one hand, they have relatively high classroom freedom to choose the approach of how to teach a certain topic. On the other hand, the rules in the educational system, defined by the government limit personal freedom regarding decision making in the case of teachers. Since control over one's work affects one's goal achievement, job control is related to personal accomplishment (Colomeischi, 2015; Leiter, 1993). To understand more deeply how individuals perform in the situation of autonomy at work, it is worth investigating personality characteristics related to autonomy. Extraversion was found to be connected with this work environment factor (Blickle et al., 2015). Since extraverts are outgoing and achievement motivated, they feel adequate and successful when they are presented with a great number of decisions. However, too little, as well as too much freedom can be frustrating. In their study, Lee and Ashforth (1993) found that role stress is a mediator for autonomy regarding burnout syndrome. It means that clear work instructions determine autonomy as a valuable influential factor for decreasing the level of burnout. In other words, when one is confused regarding one's own duties, autonomy does not result in feeling freedom, but gives an opportunity to be anxious and frustrated.

\subsubsection{Unmet expectations}

It is possible that a person's previous expectations concerning the job do not meet with reality that they experience during their work (Bracha \& Bocos, 2015). It means that individuals usually have imaginative pictures of how the work (reality) will look when acquiring a certain skill, and the reality usually turns out to be more challenging at the end. In the case of teachers, they can feel disappointed after graduation, meeting the real atmosphere of schools. In the study of Burke and Greenglass (1995), unmet expectations were found to be correlated with depersonalization. The explanation may be that by experiencing the gap between the expectations and reality, teachers may try to accommodate the reality to the idea which they have in mind, and by means of this they lose connection with their students and peers.

\subsubsection{Filling the expectations-reality gap: meaningfulness (az előző rész alpontja)}

However, Bracha and Bocos (2015) found in their study that those teaching interns who find meaning in their work, are more enthusiastic to do the job rather than feel discouraged about the gap between expectations and reality. Meaningfulness and manageability (confidence in managing the teaching tasks) were proven to be in significant correlation with all the three aspects of burnout (Bracha \& Bocos, 2015). Meaningfulness is also connected to coping strategies. According to the findings (Bracha \& Bocos, 2015), it raises the individuals' potential to actualize their coping resources. This implies that by finding meaning of work, one can overcome such obstacles that he or she did not imagine he or she would.

\subsubsection{Workload}

Perceived workload is a work stressor according to the model of Cherniss (1980 in J.Burke \& Greenglass, 1995). Workload refers to the amount of job tasks and overtime that individuals do. If a person's workload is too high, it means that there are too many demands at work and there is no time or effort to satisfy them (Fernet et al., 2012). In the case of teachers, the demands can come from the principal, students, colleagues and from parents as well. Formerly (e.g.: Alarcon et al., 2009), by exploring the individual characteristics, it was discovered that more often than not the individuals' own considerations about self is what determines of how they perceive their work environment.

\section{Criteria of the included articles}

The papers and studies referred to in the present study were selected with the help of the following search engines: ScienceDirect and Google Scholar. In order to select the correct papers the keywords were: "Maslach Burnout Inventory influencing factors", "teacher burnout risk factors", "antecedents of burnout", "teacher burnout MBI", and "teacher burnout protecting factors".

Criteria for the inclusion of the papers were: (1) the measurement method in the paper regarding the phenomenon of burnout is based on the approach of MBI, (2) the study is an empirical research, (3) the burnout components are presented separately, and (4) the study focuses on personality and/or work environment variables. Seventy articles were found and checked based on their abstracts. Among the seventy articles, fourteen met the inclusion criteria. Ten out of fourteen articles specially focused on teacher burnout. Six out of the ten 
articles about teacher burnout applied a method that investigated a causal connection between the three burnout components and the measured variables. Causal connections are important to be revealed in the present study, this way the result allows to predict whether the connection between the burnout component and other variables is positive or negative and to which extent the presented variable explains the variance of a certain burnout component. According to the investigated samples, among the six articles one was a meta-analysis which aggregated several country's results worldwide, two articles were from the US, one from Great Britain (Boston), one measured teachers' burnout in Ireland, and one of the articles compared a Swiss and an Italian sample regarding burnout.

The presented measurement tools used in the studies were linear or multiple regression analyses in order to explore the casual relations between the three factors of burnout and other measured variables (measuring either the personality characteristics or the work environment factors). The R coefficients in regression analyses describe to what extent (percentage) a certain variable explains either of the main factors of burnout. The percentage can fall between 0 and 100 and always indicates a significant relation. More detailed results can be discovered by examining the beta-coefficients which highlights the ratio of the underlying dimensions (in the case of a multi-dimensional construct).

\section{Results}

In the following, the variables related to the three dimensions of burnout will be presented one by one in order to see which factors had a major, and which factors had a lower effect on the construct of burnout.

According to the results, the following variables were significantly related to all three of the burnout dimensions (emotional exhaustion, depersonalization, personal accomplishment): positive affectivity (Alarcon et al., 2009) related negatively to emotional exhaustion, depersonalization and positively to personal accomplishment. Negative affectivity (Alarcon et al., 2009) related positively to emotional exhaustion and depersonalization and related negatively to personal accomplishment. Positive and negative affectivity together explained $32 \%$ of the variance for emotional exhaustion, $27 \%$ of the variance for depersonalization and $25 \%$ of the variance for personal accomplishment. Lack of stimulation (J.Burke \& Greenglass, 1995) related positively with emotional exhaustion and depersonalization, and negatively with personal accomplishment. As a work stressor, it explained $27 \%$ of the variance for emotional exhaustion together with conflict and ambiguity, $25 \%$ of the variance for depersonalization together with unmet expectations and narrow client contact, and $26 \%$ of the variance for personal accomplishment together with narrow client contact. Support (Mazur \& Lynch, 1989) was negatively related to emotional exhaustion and depersonalization and positively related to personal accomplishment. It explained $8 \%$ of the variance for emotional exhaustion, $4 \%$ of the variance for depersonalization and $22 \%$ of the variance for personal accomplishment. The last variable that was found to be in significant connection with all three dimensions of burnout was dissatisfaction with social support (Fiorilli et al., 2014). It was positively related to emotional exhaustion and depersonalization and negatively related to personal accomplishment. It explained $16.1 \%$ of the variance for emotional exhaustion together with emotional intensity, $11.7 \%$ of the variance for depersonalization and $10.5 \%$ of the variance for personal accomplishment together with emotional intensity. According to the results, the most influential factors of burnout syndrome are emotional aspects of the personality, and work stressors such as work stress and social support.

\subsection{Variables related to emotional exhaustion}

According to the studies, some variables were in stronger relation with emotional exhaustion than others. Work overload had the strongest connection with emotional exhaustion, explaining $41 \%$ of its variance (Mazur \& Lynch, 1989). Positive and negative affectivity together were also significant and strong predictors for emotional exhaustion, as they explained 32\% of its variance (Alarcon et al., 2009). Significant connections were found with the Five Factor Model and core self-evaluation, they explained $29 \%$ and $26 \%$ of the variance for emotional exhaustion (Alarcon et al., 2009). Among the dimensions of these measurement tools, in both cases the component of emotional stability was found to be the strongest predictor. Strong connection was found with work stressors, namely: conflict and ambiguity and lack of stimulation, as they explained $27 \%$ of the variance for emotional exhaustion (J.Burke \& Greenglass, 1995). Another variable from the same study, social support explained $28 \%$ of the variance for emotional exhaustion (J.Burke \& Greenglass, 1995). Relatively strong relations of emotional exhaustion and the school's climate factors were reported in the study of Grayson and Alvarez (2008): in this research two variables, parent community and student peer relations explained together $12.7 \%$ of the variance for emotional exhaustion. A moderate connection was observed in the case of emotional intensity and dissatisfaction with social support in the study of Fiorilli et at (2014). Together, they explained $16.1 \%$ of the variance for emotional exhaustion. Regarding this burnout factor, still significant but weak connections were found with the following variables: student relations explained 1.4\% (Foley \& Murphy, 2015), neuroticism explained 6\% (Foley \& Murphy, 2015), isolation explained 4\% (Mazur \& Lynch, 1989), support explained 8\% (Mazur \& Lynch, 19899), empathic self-concept explained 2\% (Mazur \& Lynch, 1989), Type A personality explained 3\% (Mazur \& Lynch, 1989), primary subject explained 1\% (Mazur \& Lynch, 1989), and having 
hypertension or/and "other diseases" previously in one's life both explained 1\%-1\% of the variance for emotional exhaustion (Mazur \& Lynch, 1989).

\subsection{Variables related to depersonalization}

Regarding depersonalization, the following variables were found to be the strongest predictors in the studies: positive and negative affectivity together explained $27 \%$ of the variance for depersonalization, where the effect of the two phenomena was similar according to the beta coefficients of the regression analysis (Alarcon et al., 2009). The Five Factor Model explained $26 \%$ of the variance for depersonalization, among the personality factors emotional stability and agreeableness were the strongest predictors (Alarcon et al., 2009). The work stressor variables, such as unmet expectations, lack of stimulation and narrow client contact together explained $25 \%$ of the variance for depersonalization (J.Burke \& Greenglass, 1995). Relatively strong predictor was core selfevaluation (17\%), and out of its components emotional stability had the strongest relation with depersonalization (Alarcon et al., 2009). Anomie (a state or condition of individuals) seemed to play a rather high role in defining this dimension of burnout, as it explained 14\% of the variance for depersonalization (Mazur \& Lynch, 1989). According to the school's climate factors, administration, teacher student relations and student academic orientation together explained 14\% of the variance for depersonalization (Grayson \& Alvarez, 2008). In another study, gender and dissatisfaction with social support together explained $11.7 \%$ of the variance for depersonalization (Fiorilli et al., 2014). Regarding this construct, other significant relations resulted in the following: type of school explained 10\% (J.Burke \& Greenglass, 1995), responsibility (as an organizational factor) explained 9\%, support explained 4\% (Mazur \& Lynch, 1989), self-esteem explained 4\% (Mazur \& Lynch, 1989), and order and organization (as a classroom condition) explained 3.4\% (Foley \& Murphy, 2015), in another study core self-evaluation explained 3.8\% (Foley \& Murphy, 2015), extraversion explained 2.5\% (Foley \& Murphy, 2015), avoidance coping (as a form of emotional coping) explained 1.5\% (Foley \& Murphy, 2015), student ability level explained 2\% (Mazur \& Lynch, 1989), and having cancer or heart disease previously in one's life both explained 2\%-2\% of the variance for depersonalization (Mazur \& Lynch, 1989).

\subsection{Variables related to personal accomplishment}

The level of personal accomplishment was strongly related to core self-evaluation, it explained $30 \%$ of the variance for this dimension of burnout, where self-esteem was the strongest predictor according to the betacoefficients of the measure (Alarcon et al., 2009). Work stressors were also in strong connection with personal accomplishment: narrow client contact and lack of stimulation - the latter two are to be interpreted in the classroom environment - together explained $26 \%$ of the variance for this dimension of burnout (J.Burke \& Greenglass, 1995). Another strong predictor was positive and negative affectivity, together they explained 25\% of the variance for personal accomplishment, where positive affectivity had a much stronger effect according to the beta coefficients of the regression analysis (Alarcon et al., 2009). The Five Factor Model explained $23 \%$ of the variance for personal accomplishment, where the extraversion factor was the strongest predictor (Alarcon et al., 2009). The support variable in the study of Mazur and Lynch (1989) explained $11 \%$ of the variance for personal accomplishment. Emotional intensity and dissatisfaction with social support together explained $10.5 \%$ of the variance for the same dimension of burnout (Fiorilli et al., 2014). Other relations with personal accomplishment were found between the following variables: teacher self-efficacy explained 5.2\% (Foley \& Murphy, 2015), responsibility (as an organizational factor) explained 9\% (Mazur \& Lynch, 1989), self-esteem explained 6\% (Mazur \& Lynch, 1989), classroom interactions explained 3.8\% (Foley \& Murphy, 2015), instructional management (as a school's climate factor) explained 6.5\% (Grayson \& Alvarez, 2008), problem-focused coping explained 1.5\% (Foley \& Murphy, 2015), extraversion explained 1.2\% (Foley \& Murphy, 2015), order and organization (as a classroom condition) explained 1.8\% (Foley \& Murphy, 2015), anomie explained 3\% Mazur \& Lynch, 1989), and having hypertension, heart disease or other diseases previously in one's life explained $2 \%$ and $1 \%$ and $2 \%$ of the variance for personal accomplishment (Mazur \& Lynch, 1989).

\section{Discussion}

\subsection{Personality factors}

Personality characteristics were found to represent a major proportion of the influencing variables, namely the Five Factor Model, core self-evaluation, positive affectivity, and negative affectivity, according to the study of Alarcon et al. (2009).

\subsubsection{Five factor model}

Among the dimensions of the Five Factor Model, emotional stability was the strongest construct relating both to emotional exhaustion and depersonalization. By emotional exhaustion, the connection with emotional stability (or in other words neuroticism) was confirmed in the study by Foley and Murphy, however with a less stronger regression coefficient (Foley \& Murphy, 2015). Depersonalization also correlated strongly with agreeableness in the Five Factor Model. For personal accomplishment, extraversion seemed to be the most 
determining factor out of the dimensions of the Five Factor Model. As the previous studies discussed, emotional aspects of the syndrome are the first signs of burnout and are strongly connected to emotional exhaustion. According to Alarcon's results, it is also proven that the same factors correlate with emotional exhaustion and depersonalization, and this indicates that these two dimensions have more in common compared to the concept of personal accomplishment. Respectfully to this result, it is worth to mention that personal accomplishment and depersonalization both were found to be influenced by the extraversion dimension of the Five Factor Model (Foley \& Murphy, 2015), however in a less strong relation than in the case of the meta-analysis of Alarcon et al. (2009).

\subsubsection{Core self-evaluation}

Out of the CSE components, emotional stability rose above the other constructs as an influencing factor in the case of emotional exhaustion and depersonalization, strengthening the hypothesis that both of these constructs are connected to emotional aspects of the personality. According to CSE, self-esteem was proven to have the strongest influence on the level of personal accomplishment. Other studies also investigated the influencing level of self-esteem. Mazur and Lynch (1989) explored the effects of this variable as a part of "Selfconcept", which is an umbrella-concept similar to CSE, and has three components: self-esteem, idealized self and empathic self. It was found that self-esteem is connected both to depersonalization and personal accomplishment. Self-esteem is a phenomenon that anticipates one's consideration about self-worth (Mazur \& Lynch, 1989), thus the result can imply that personal accomplishment and depersonalization has a common aspect regarding the individuals' own considerations about their worthiness.

\subsubsection{Positive affectivity and negative affectivity}

Positive affectivity and negative affectivity were found to be in strong relation with all three dimensions of burnout syndrome. According to the meta-analysis of Alarcon et al. (2009), positive affectivity was in stronger connection with personal accomplishment, and emotional exhaustion was influenced more by negative affectivity. Depersonalization was found to be equally influenced by both positive and negative affectivity. The results imply that experiencing positive emotions have a positive impact on feeling personal accomplishment, and having the tendency to experience negative emotions resulted in emotional exhaustion. In all dimensions of burnout it is true that they are influenced by the affective aspects of the personality, and one's type of affectivity can be considered as a sign for either the tendency of developing the syndrome or not.

\subsubsection{Coping strategies}

Coping strategies were found to be significantly related to two of the burnout factors (depersonalization and personal accomplishment), however, the indicators were not high according to the studies (Foley \& Murphy, 2015). Avoidance coping, as a type of emotion-focused coping was related to depersonalization and problemfocused coping was related to personal accomplishment. Both of the concepts were in positive relation with the burnout dimensions. The results strengthen the hypothesis that depersonalization is related to the maladaptive strategies of handling a situation, and the individuals' level of personal accomplishment is protected if they are able to actualize adaptive solutions for a given challenging situation.

\subsubsection{Other personality factors}

In the following there will be other personality characteristics introduced which were found to be less strongly connected to the burnout dimensions, yet indicate notable relations.

The concept of Type A/B personality was investigated by Mazur and Lynch and found to be connected with emotional exhaustion. Individuals with type A personality tend to be hostile, aggressive and impatient, perceive the work environment negatively and usually selecting jobs that are stressful (Alarcon et al., 2009). At the same time type-A personality anticipates that the person is achievement-oriented. This personality trait is often connected with hypertension and coronary heart disease (Rosenman, Brand, Sholtz, \& Friedman, 1976). According to Mazur \& Lynch, in the case of emotional exhaustion this personality trait can cause that individuals overburden themselves, they do not care about their own emotional needs. On the other hand, there is another considerable relation found between the burnout dimensions and type A personality. In the meta-analysis of Alarcon et al., type A personality was found to be positively correlated with the level of personal accomplishment (Alarcon et al., 2009). According to the definition of type A personality, the inner passion of achievementorientation may be the explanation for strengthened personal accomplishment.

Empathic self, as the component of the term "Self-concept" was found to be related with emotional exhaustion in the study of Mazur and Lynch (1989). This personality characteristic refers to a subjective evaluation of the individuals regarding their social acceptance and reciprocity in their connections. The individuals' evaluation can depend on their own considerations of themselves. In the case of high empathic self, individuals perceive a failed interaction as a mistake to learn from and in the opposite case they consider it as a sign to back up and withdraw from the task or challenge.

The concept of anomie was investigated by Mazur and Lynch (1989), and was found to be a relatively strong influencing factor for depersonalization. It also determined the level of personal accomplishment, on a 
lower rate. Anomie refers to a sense of meaningless and alienation. Individuals with high level of anomie may feel that they are solitary figures in the team (Mazur \& Lynch, 1989). This negative feeling of self can develop into a negative attitude toward others, thus the level of depersonalization may increase. Regarding personal accomplishment, the feeling of no purpose can be mentioned as a contributing factor in the concept of anomie.

Emotional intensity was a concept investigated by Fiorilli et al. (2014). In their study cultural differences between a Swiss and an Italian sample were explored regarding teacher burnout. Emotional intensity is a concept that describes how an emotional experience is interpreted at the cognitive level (Fiorilli et al., 2014). It is a component of another phenomenon, that of emotional competence. According to the results of the study, the level of emotional intensity was related to emotional exhaustion and personal accomplishment. Emotional intensity can be a mediating factor between work environment and burnout, because it is a tendency of how an individual takes on his or her experiences.

In their study, Foley \& Murphy (2015) investigated the phenomenon of teachers' self-efficacy and it was found to be related to the level of personal accomplishment. According to the results, the level of personal accomplishment is significantly connected to the subjective level of performance in teaching. Teachers who perceive themselves less effective as a professional, face the risk of reduced personal accomplishment.

The preceding results strengthen the idea that burnout development is based on individual characteristics, because most of the studies found significant relations between personality factors and burnout dimensions, and according to the tendencies, the influencing ratio was relatively high in all cases.

\subsection{Work stressors}

\subsubsection{Workload}

Among the work stressors, perceived workload had the greatest impact on the dimension of emotional exhaustion, and influenced this burnout factor with the strongest regression coefficient among all. It is proven by this result that workload is a determining factor for the development of the syndrome. However, the results show that not only work overload is connected with burnout, but lack of stimulation as well. In fact, according to Burke and Greenglass' (1995) results, this variable significantly related to all three dimensions of burnout. According to these results, it can be concluded that not only work overload but little or no challenge at work also has an emotionally demanding aspect. However, both results can be seen as perceived characteristics of work (by the individual) by means that personality is the core factor according to which challenges in life are evaluated. The perceived workload is connected with the level of how much responsibility the individual is willing to take and the perceived role stress that the individual experiences. Thus, role stress and responsibility can be moderating factors between burnout and perceived workload.

\subsubsection{Social support}

Social support was found to be an explaining factor for all the three dimensions of burnout (Mazur \& Lynch, 1989). Social support is a protecting factor for emotional exhaustion and depersonalization and a strengthening factor of personal accomplishment. The influence of dissatisfaction with social support (Fiorilli et al., 2014) was also investigated. It was related to all three dimensions of burnout, and reassured what Lee and Ashforth stated in their study (1993), that the availability of social support is more important than support itself.

\subsubsection{The school as an environment for teaching}

School climate factors were investigated in the study of Grayson and Alvarez (2008). They are important situational variables regarding the teaching profession, as they are describing the characteristics of the classroom and the school as an organizational background for teaching. Emotional exhaustion was found to be related with parent community and student-peer relations. Parent community means that there is a good community in the school, and parents are open to participate in programs organized by the school. Student-peer relations refers to the students' relations with each other implying that they have respect toward each other and students have a sense of belonging to the school.

With depersonalization, administration, teacher-student relations and academic orientation were related. Administration means that the school requires high administrative standards, and everyone is wellinformed and supported to achieve them. The teacher-administrator connection was shown to be an important part of the teachers' feeling of connectedness and belonging to the organization (Grayson \& Alvarez, 2008). The other factor, academic orientation refers to students' interest in learning, their willingness to work hard on their assignments and assumes that students have an understanding of why they are in school and what their long-term goals are in life. In their study, Mazur and Lynch also found that students' ability level explains the variance for depersonalization, strengthening this result (Mazur \& Lynch, 1989). The third factor, teacher-student relations refers to the amount of positive interactions shared between the students and the teacher and measures the degree of the teachers' willingness to understand and meet students' needs (Grayson \& Alvarez, 2008). Confirming this result, in another study, Rouxel et al. (2016) observed the effect of "positive display of rules". Geriatric nurses' (who were the subject of observation) job tasks include the expression of positive emotions, even if it does not come naturally. According to the results, expressing positive feelings had a protecting effect regarding 
burnout syndrome. When nurses expressed comforting gestures toward others, even if they felt tired, they got positive feedback which decreased the level of emotional exhaustion (Rouxel et al., 2016).

Regarding school climate factors, the third dimension of burnout, personal accomplishment was related to instructional management (Grayson \& Alvarez, 2008). This classroom factor has three components: (1) the amount of clearly identified rules for students at school, (2) the amount of classroom activities spent with learning, (3) and the amount of outside interruptions (Grayson \& Alvarez, 2008). The factor of instructional management is connected to the feeling of self-efficacy, as more quality time spent in the classroom with less interruptions resulted in feeling of personal accomplishment and being efficient as a teacher.

Summarizing the effects of school climate factors in the study of Grayson and Alvarez (2008), emotional exhaustion was found to be in connection with the work activity. This refers to the direct connection with the students and parents as the "elements" of the school environment. Depersonalization was proven to be connected with interpersonal variables, and members of the school system. The difference between the factors connected with emotional exhaustion and depersonalization is that with depersonalization the context of the connection (i.e. either well-built and reliable system, or precarious, undefined rules) is more emphasized. In the case of personal accomplishment, the behavior aspect is the strongest which manifests in how effectively a teacher can manage time in the classroom, which in turn reflects his or her self-efficacy (Grayson \& Alvarez, 2008).

Apart from the research of Grayson and Alvarez (2008), other studies have also found relations between burnout syndrome and classroom environment factors. In their study, Burke and Greenglass (1995) found that narrow client contact explains a relatively big part in the dimension of depersonalization and personal accomplishment. This variable means that the problem that has to be solved at work is limited to a small variability, in other words it is monotonous (J.Burke \& Greenglass, 1995). It should also be noted that in the case of teachers, the work is carried out in cooperation with other individuals. According to the results, teachers who feel that they face the same kind of problems in the classroom day by day, are more at risk of being depersonalized and having lower personal accomplishment.

In their study, Foley and Murphy (2015) measured burnout syndrome experienced by teachers from different schools in Ireland. They discussed the work environment (school) as a holistic system, where the parts of the system affect each other. They defined the features of "low burnout schools" or respectively "high burnout schools". In "low burnout schools" - according to Foley and Murphy -, teachers contribute to decision making, have daily contact with the principal and the school does not have a very tight structure. In "high burnout schools" there is a rigid management structure, the decisions are made by the principal and teachers do not work as a team, but separately (Foley \& Murphy, 2015). Going into more details, in his study, Suplicz (2012), defined the characteristics of "good teachers" and "bad teachers". According to his results, students can connect to and appreciate their teacher at most through the teacher's personality. In his study, Suplicz found that the instructional methods applied by teachers and the amount of knowledge possessed by them are both explained by the teacher's personality (Suplicz, 2012), thus the teachers' personality traits are moderators between their success among students and their knowledge as a professional.

\subsubsection{Organizational factors}

In the studies, significant relationships were found between the organizational factors and burnout. Conflict and ambiguity explained the changes in the level of emotional exhaustion (J.Burke \& Greenglass, 1995). These constructs were identified as factors of role stress (Alarcon et al., 2009) and these variables were found to contribute to the development of emotional exhaustion in the previous examinations as well.

Isolation also had an impact on the level of emotional exhaustion (Mazur \& Lynch, 1989). Since social support was a significant determining factor for emotional exhaustion, being isolated can put individuals at risk of developing burnout. Mazur and Lynch found relations between the primary subject of the teacher and emotional exhaustion as well, however, the regression coefficient was rather low in this case Mazur \& Lynch, 1989).

For depersonalization, unmet expectations were found to be an influencing factor according to the results of Burke and Greenglass (1995). As it could be seen in the theoretical review, unmet expectations can be frustrating for the individuals, and in the case of lacking adaptive coping strategies, they can turn to maladaptive styles, such as depersonalization. The same study found another significant risk factor regarding depersonalization, that is the type of school (J.Burke \& Greenglass, 1995).

Responsibility also explained the variance for depersonalization (Mazur \& Lynch, 1989). It means, that the individuals' own consideration about how much responsibility they can take is influencing their interpersonal activity. Responsibility was related to the level of personal accomplishment as well (Mazur \& Lynch, 1989). The factor that connects these two can be self-efficacy, because more responsibility means more control over the tasks at work, and it works as a triggering factor for personal accomplishment only when self-efficacy is high.

\subsubsection{Health factors}

According to the results (Mazur \& Lynch, 1989), physical health factors (e.g.: heart disease, cancer, hypertension and other diseases) influence all three dimensions of burnout significantly, yet not on a considerably 
high level. Health can be a supplementary factor, a symptom of experiencing burnout, but cannot be taken as an individual characteristic that determines the syndrome. Besides, Burke and Greenglass (1995) found that physical health had no correlation with burnout, strengthening the hypothesis that there is little determining value of health by itself regarding the development of burnout.

\subsubsection{A suggested model for burnout development including personality- and work environment factors}

It can be seen regarding the discussion section, that social support have a huge preventing effect on the development of burnout. However, when we look at the individual separately from others, his or her personality characteristics determine how he or she perceives the working environment (along with the professional challenges and stress factors at work). Among personality factors, emotional characteristics of the personality were dominant in handling emotional stress at work. Even by choosing a place to work, individuals with positive affectivity have better chance to perform well on job interviews, thus have more job offers from which they can decide for the most favorable job for themselves (Alarcon et al., 2009). At the workplace, people with positive affectivity look for exciting and stimulating environment, and challenges that exceed their competence, thus they can evolve as a professional by stepping out of their comfort zone (Alarcon et al., 2009). Moreover, individuals with positive affectivity are more likely to experience positive emotions and optimism (Alarcon et al., 2009). Among the factors of the FFM, emotional stability was proven to have preventing effect on experiencing emotional exhaustion (Alarcon et al., 2009). The research of Ju et al (2015) implies, that individuals who have high emotional intelligence, will most likely to notice social support in the work environment.

Based on the theory of burnout development of Leiter (Leiter, 1993), emotional exhaustion is the first phenomena that occurs during the process of job burnout. Consequently, individuals who are successful in managing emotional challenges at work - in the manner described above - will be protected from getting to the crisis point of emotional exhaustion. Thus, they are successful in coping with adaptive solutions, and have enough self-esteem to feel confident and "on the top of their game".

Our suggested model focuses on this interaction of emotional characteristics of the personality, and the self-confidence that results in applying effective coping mechanisms of the work environment. First, individuals' emotional traits define how they react in a given situation at work - step (1) and (2) of the model. Then, they decide, whether or not they feel effective in coping with a challenge at work (step (3)). At step (4), individuals act (cope), by either applying or actualize an adaptive coping strategy, or, giving up, by feeling incompetent in the situation, which leads to applying maladaptive coping strategy (such as depersonalization). At step (5) the level of burnout will either increase or decrease.

For the confirmation of this suggested model, which is based on the results of the reviewed articles, applying bottom-up research (e.g.: semi-structured interviews) could provide a solution, beginning with finding one's character-strengths.

\section{Limitations}

A substantial level of homogeneity was observed within the results of the regression analyses in the results of the reviewed studies compared to the values of the coefficients between

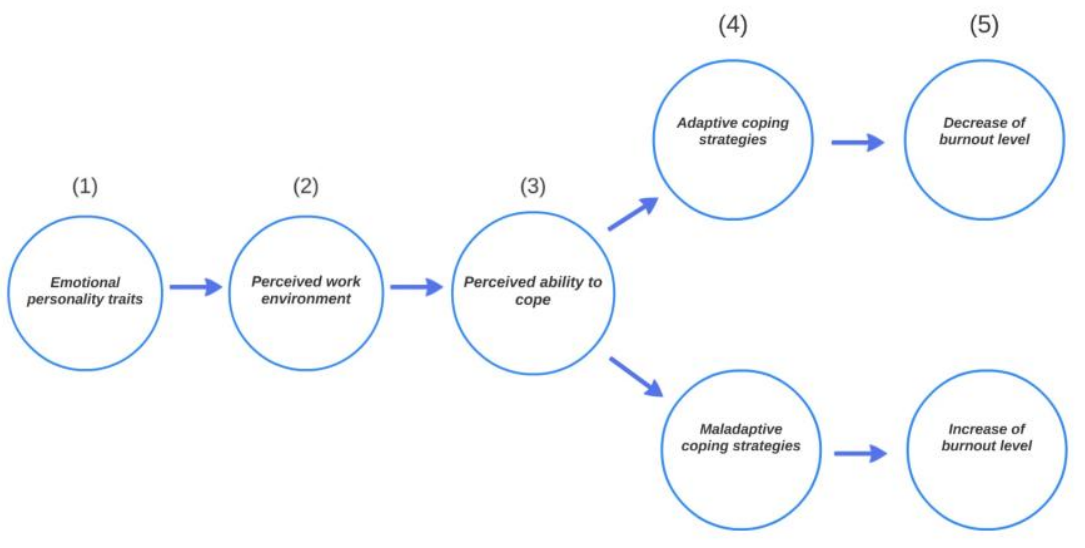

Figure 1: Suggested model for burnout development

different studies. This result is due to the different sample involved in the researches. However, multiple regression analysis is one of the most reliable measuring methodology and the results found in the reviewed studies seemed to reinforce each other apart from some exceptions (e. g.: in the case of type A personality). Explaining these exceptions, may give a fertile ground for further investigations.

Returning back to our suggested model, the other subject of further investigations might be to develop a method in order to strengthen the emotional traits of the individuals (e.g.: emotional intelligence training).

The overall results of this review article point out, that burnout can be handled best at an early phase, when the effects of emotional exhaustion have not yet changed one's own considerations about self (i.e. the emotional effects have no consequences yet on the cognitive level). In an early phase, it is possible to turn back the current of the syndrome by individual improvement. According to Leiter (in Maslach et al., 2001) there are two ways of handling persistent aspects of the work environment: one is to develop high personal efficiency (applying and learning new coping mechanisms with the change) and the other way is developing burnout syndrome. It is better for all concerned to realize sooner than later the appearance of burnout. 
As Leiter suggested in his work (Leiter, 1993) about burnout syndrome, the opposite end on the continuum of burnout is effective personal involvement. The ultimate purpose of further investigations is that there would be more and more teachers who are able to shine their light through by inspiring students with their enthusiasm and professional knowledge, and to have fewer teachers at the other side of the candle.

\section{Acknowledgements}

The authors would like to express their gratitude to Budapest University of Technology and Economics for providing all the required resources for the article to be written.

\section{References}

Alarcon, G., Eschleman, K. J., \& Bowling, N. A. (2009). Relationships between personality variables and burnout: A meta-analysis. Work \& Stress, 23(3), 244-263. https://doi.org/10.1080/02678370903282600

Bergner, T. H. (2012). Burnout - A kiégés megelőzése 12 lépésben. Retrieved from https://www.zpress.hu/burnout-kieges-megelozese-12-lepesben-konyv

Blickle, G., Meurs, J. A., Wihler, A., Ewen, C., Merkl, R., \& Missfeld, T. (2015). Extraversion and job performance: How context relevance and bandwidth specificity create a non-linear, positive, and asymptotic relationship. Journal of Vocational Behavior, 87, 80-88. https://doi.org/10.1016/j.jvb.2014.12.009

Bracha, E., \& Bocos, M. (2015). A Sense of Coherence in Teaching Situations as a Predictor of First Year Teaching Interns' Burnout. Procedia - Social and Behavioral Sciences, 209(July), 180-187. https://doi.org/10.1016/j.sbspro.2015.11.276

Bruce. (1996). Understanding and Minimizing Staff Burnout. Retrieved from http://smhp.psych.ucla.edu

Byrne, B. M. (1991). Burnout: Investigating the impact of background variables for elementary, intermediate, secondary, and university educators. Teaching and Teacher Education, 7(2), 197-209. https://doi.org/10.1016/0742-051X(91)90027-M

Cañadas-De la Fuente, G. A., Vargas, C., San Luis, C., García, I., Cañadas, G. R., \& De la Fuente, E. I. (2015). Risk factors and prevalence of burnout syndrome in the nursing profession. International Journal of Nursing Studies, 52(1), 240-249. https://doi.org/10.1016/j.ijnurstu.2014.07.001

Colomeischi, A. A. (2015). Teachers Burnout in Relation with Their Emotional Intelligence and Personality Traits. Procedia - Social and Behavioral Sciences, 180(November 2014), 1067-1073. https://doi.org/10.1016/j.sbspro.2015.02.207

Demerouti, E.; Bakker, A.B.; Nachreiner, F.; Schaufeli, W. B. (2001). The Job Demands-Resources Model of Burnout. Journal of Applied Psychology. https://doi.org/10.1037//0021-9010.86.3.499

Fernet, C., Guay, F., Senécal, C., \& Austin, S. (2012). Predicting intraindividual changes in teacher burnout: The role of perceived school environment and motivational factors. Teaching and Teacher Education, 28(4), 514-525. https://doi.org/10.1016/j.tate.2011.11.013

Fiorilli, C., Gabola, P., Pepe, A., Meylan, N., Curchod-Ruedi, D., Albanese, O., \& Doudin, P. A. (2014). The effect of teachers' emotional intensity and social support on burnout syndrome. A comparison between Italy and Switzerland. Revue Europeene de Psychologie Appliquee, 65(6), 275-283. https://doi.org/10.1016/j.erap. 2015.10 .003

Foley, C., \& Murphy, M. (2015). Burnout in Irish teachers: Investigating the role of individual differences, work environment and coping factors. Teaching and Teacher Education, 50, 46-55. https://doi.org/10.1016/ j.tate.2015.05.001

Freudenberger, H. J. (1974). Staff Burn-Out. Journal of Social Issues, 30(1), 159-165. https://doi.org/10.1111/j. 1540-4560.1974.tb00706.x

Gil-Monte, P., Peiro, J. M., \& Valcárcel, P. (1998). A model of burnout process development: An alternative from appraisal models of stress. Comportamento Organizacional E Gestão, 4(1), 165-179.

Goddard, R., O'Brien, P., \& Goddard, M. (2006). Work environment predictors of beginning teacher burnout. British Educational Research Journal, 32(6), 857-874. https://doi.org/10.1080/01411920600989511

Goetz, T., Becker, E. S., Bieg, M., Keller, M. M., Frenzel, A. C., \& Hall, N. C. (2015). The glass half empty: How emotional exhaustion affects the state-trait discrepancy in self-reports of teaching emotions. PLOS ONE, 1O(9). https://doi.org/10.1371/journal.pone.0137441

Grayson, J. L., \& Alvarez, H. K. (2008). School climate factors relating to teacher burnout: A mediator model. Teaching and Teacher Education, 24(5), 1349-1363. https://doi.org/10.1016/j.tate.2007.06.005

Hayes, M. W. (2013). The Challenge of BURNOUT: An Ethical Perspective. Annals of Psychotherapy \& Integrative Health. Retrieved from http://search.ebscohost.com.ezproxy.montclair.edu:2048/login.aspx?direct=true\& $\mathrm{db}=\mathrm{aph} \& \mathrm{AN}=91511560 \&$ site $=$ ehost-live $\&$ scope $=$ site

Hurtz, G. M., \& Donovan, J. J. (2000). Personality and job performance: the Big Five revisited. The Journal of Applied Psychology, 85(6), 869-879. https://doi.org/10.1037/0021-9010.85.6.869

J.Burke, R., \& Greenglass, E. (1995). A Longtitudinal Study of Psychological Burnout in Teachers. Human Relations, 48(2), 187-202. https://doi.org/0803973233

Ju, C., Lan, J., Li, Y., Feng, W., \& You, X. (2015). The mediating role of workplace social support on the relationship 
between trait emotional intelligence and teacher burnout. Teaching and Teacher Education, 51, 58-67. https://doi.org/10.1016/j.tate.2015.06.001

Judge, T. A., Bono, J. E., Erez, A., \& Locke, E. A. (2005). Core Self-Evaluations and Job and Life Satisfaction: The Role of Self-Concordance and goal attainment. Journal of Applied Psychology, 90(2), 257-268. https://doi.org/10.1037/0021-9010.90.2.257

Laugaa, D., Rascle, N., \& Bruchon-Schweitzer, M. (2008). Stress and burnout among French elementary school teachers: A transactional approach. Revue Europeene de Psychologie Appliquee, 58(4), 241-251. https://doi.org/10.1016/j.erap.2008.09.007

Leary, T. (1957). Interpersonal diagnosis of personality. New York: Ronald Press. in McCrae, R. R., \& John, O. P. (1992). An Introduction to the 5-Factor Model and its Applications. Journal of Personality, 60(2), 175-215. https://doi.org/10.1111/j.1467-6494.1992.tb00970.x

Lee, R. T., \& Ashforth, B. E. (1993). A Longitudinal Study of Burnout among Supervisors and Managers: Comparisons between the Leiter and Maslach (1988) and Golembiewski et al. (1986) Models. Organizational Behavior and Human Decision Processes. https://doi.org/10.1006/obhd.1993.1016

Leiter, M. P. (1993). Burnout as a developmental process: Consideration of models. Professional Burnout: Recent Developments in Theory and Research.

Maslach, C., Schaufeli, W. B., \& Leiter, M. P. (2001). Job Burnout. Annual Review Psychology, 52, 397-422. https://doi.org/10.1146/annurev.psych.52.1.397

Mazur, P. J., \& Lynch, M. D. (1989). Differential impact of administrative, organizational, and personality factors on teacher burnout. Teaching and Teacher Education, 5(4), 337-353. https://doi.org/10.1016/0742051X(89)90031-0

McCrae, R. R., \& John, O. P. (1992). An Introduction to the 5-Factor Model and its Applications. Journal of Personality, 60(2), 175-215. https://doi.org/10.1111/j.1467-6494.1992.tb00970.x

Mittal, M., \& Chhabra, S. (2011). A Study of Emotionlal Labor and Burnout Symptoms in Teachers. Global Management Review.

Mollart, L., Skinner, V. M., Newing, C., \& Foureur, M. (2013). Factors that may influence midwives work-related stress and burnout. Women and Birth, 26(1), 26-32. https://doi.org/10.1016/j.wombi.2011.08.002

Reis, D., Xanthopoulou, D., \& Tsaousis, I. (2015). Measuring job and academic burnout with the Oldenburg Burnout Inventory (OLBI): Factorial invariance across samples and countries. Burnout Research, 2(1), 8-18. https://doi.org/10.1016/j.burn.2014.11.001

Rosenman, R. H., Brand, R. J., Sholtz, R. I., \& Friedman, M. (1976). Multivariate prediction of coronary heart disease during 8.5 year follow-up in the Western Collaborative Group Study. American Journal of Cardiology, 37(6), 903-910. https://doi.org/10.1161/01.CIR.53.2.348

Rouxel, G., Michinov, E., \& Dodeler, V. (2016). The influence of work characteristics, emotional display rules and affectivity on burnout and job satisfaction: A survey among geriatric care workers. International Journal of Nursing Studies, 62, 81-89. https://doi.org/10.1016/j.ijnurstu.2016.07.010

Sas, C., Boroș, D., \& Bonchiş, E. (2011). Aspects of the burnout syndrome within the teaching staff. Procedia - Social and Behavioral Sciences, 11, 266-270. https://doi.org/10.1016/j.sbspro.2011.01.074

Schaufeli, W.B.; Buunk, B. P. (1996). Professional Burnout. John Wiley \& Sons Ltd.

Skodova, Z., \& Lajciakova, P. (2013). The effect of personality traits and psychosocial training on burnout syndrome among healthcare students. Nurse Education Today, 33(11), 1311-1315. https://doi.org/10.1016/j.nedt.2013.02.023

Sun, L., Gao, Y., Yang, J., Zang, X.-Y., \& Wang, Y.-G. (2016). The impact of professional identity on role stress in nursing students: A cross-sectional study. International Journal of Nursing Studies, 63, 1-8. https://doi.org/10.1016/j.ijnurstu.2016.08.010

Wilt, J., \& Revelle, W. (2009). Extraversion. Handbook of Individual Differences in Social Behavior, 111(1), 1. https://doi.org/10.1037/a0022884 